\title{
DBPig \\ The Effect of Water-Soluble Calcium Supplements on Calcium Metabolism and Bone Metabolism of Growing Rats
}

\section{저자}

(Authors)

출처

(Source)

\section{발행처}

(Publisher)

URL

APA Style

이용정보

(Accessed)
Se-Young Jang, Yong-Jin Jeong, Teak-Kyu Kwon, Ji-Hyung Seo, Eun-Mi Park

Preventive Nutrition and Food Science 12(4), 2007.12, 217-221 (5 pages)

한국식품영양과학회

The korean Society of Food Science and Nutrition

http://www.dbpia.co.kr/Article/NODE00932926

Se-Young Jang, Yong-Jin Jeong, Teak-Kyu Kwon, Ji-Hyung Seo, Eun-Mi Park (2007). The Effect of Water-Soluble Calcium Supplements on Calcium Metabolism and Bone Metabolism of Growing Rats. Preventive Nutrition and Food Science, 12(4), 217-221.

계명대학교

114.71.5.212

2016/01/13 14:03 (KST)

\section{저작권 안내}

$\mathrm{DBpia}$ 에서 제공되는 모든 저작물의 저작권은 원저작자에게 있으며, 누리미디어는 각 저작물의 내용을 보증하거나 책임을 지지 않습니다.

이 자료를 원저작자와의 협의 없이 무단게재 할 경우, 저작권법 및 관련법령에 따라 민, 형사상의 책임을 질 수 있습니다.

\section{Copyright Information}

The copyright of all works provided by DBpia belongs to the original author(s). Nurimedia is not responsible for contents of each work. Nor does it guarantee the contents.

You might take civil and criminal liabilities according to copyright and other relevant laws if you publish the contents without consultation with the original author(s). 


\title{
The Effect of Water-Soluble Calcium Supplements on Calcium Metabolism and Bone Metabolism of Growing Rats
}

\author{
Se-Young Jang, Yong-Jin Jeong, Teak-Kyu Kwon ${ }^{1}$, Ji-Hyung Seo ${ }^{2 \dagger}$, and Eun-Mi Park ${ }^{3}$ \\ Department of Food Science and Technology, Keimyung University, Daegu 704-701, Korea \\ ${ }^{1}$ Department of Immunology, College of Medicine, Keimyung University, Daegu 700-712, Korea \\ ${ }^{2}$ Division of Food, Beverage \& Culinary Arts, Yeungnam College of Science \& Technology, Daegu 705-703, Korea \\ ${ }^{3}$ Efficacy and Safety Research Center for Traditional Oriental Medicine, Daegu Haany University, Gyeongbuk 712-715, Korea
}

\begin{abstract}
Within the elderly population, the use of calcium supplements and the intake of calcium from food are on the rise in order to maintain health. Calcium is absorbed as an ion in vivo, leading to speculation that absoption efficiency is affected by the solubility of the calcium consumed. In our study, the bioavailability of two types of calcium supplements with different solubilities was evaluated. Expenimental animals were fed water-soluble or insoluble calcium supplements for 6 weeks. We found that blood alkali phosphatase activity, osteocalcin content, and urine crosslinks values were not different between the groups. Similarly, the degree of apparent calcium absoption between the two calcium supplements was not significantly different. The bone mineral density and bone mineral content of the femur and the tibia increased in the group that consumed insoluble calcium compared with those of the water-soluble calcium supplemented group. However, when considering body weight, the bone mineral density value for all areas, including the spine, was significantly higher in the group that consumed the water-soluble calcium supplement.
\end{abstract}

Key words: calcium supplement, water-soluble calcium, calcium absorption, bone mineral density, calcium carbonate

\section{INTRODUCTION}

With the prolongation of the average life-span, as society ages the intake of sufficient calcium is often emphasized. Calcium is the most abundantly distributed mineral in the human body, present primarily in the bones and teeth, but also in body fluids for performing functions of physiological signaling and control (1). Long-term calcium deficiency can lead to osteoporosis, and may also have mediating effects on the development of hypertension, colorectal cancer, etc. $(2,3)$. As a result, there is great interest in calcium supplement use, as well as the intake of calcium in foods.

Calcium supplements are classified as natural supplements derived from shells, eggshells, etc., or as synthetic supplements such as calcium carbonate, calcium citrate, etc. The use of inexpensive calcium supplements is common, and the representative calcium supplement in this category, calcium carbonate, has a very low solubility. Previously, interest in calcium was focused on increasing the level of calcium intake, and most studies looked at physiological changes based on a level of calcium intake (4-6). It has now been recognized that the bioavailability of calcium is low compared to other minerals. Recently, it was reported that calcium citrate supplements have a high solubility and can have excellent effects (7-9). Therefore, there is speculation that calcium's efficacy may be influenced by its solubility and the degradation of the supplement in the body. In other words, calcium absorption may depend on its dissociation to the ion form, and as a supplement's solubility becomes higher, its ionization may be accelerated allowing calcium to be absorbed faster. On the other hand, some researchers have reported that the absorption rate of calcium is not associated with the supplement's properties $(10,11)$. Therefore, studies on the bioavailability of calcium supplements must focus on a variety of aspects.

In this study, we evaluated the physiological efficiency of calcium supplements based on their solubility. Here, experimental animals were supplemented with a water-soluble calcium supplement or insoluble calcium supplement, and their biochemical markers and changes in bone mineral density examined.

\section{MATERIALS AND METHODS}

Expenimental animals and diet

In this study, growing female rats, for which the ad- 
ministration of liquid calcium supplement was feasible and calcium metabolism was active, were selected as experimental animals. Thirty female Sprague-Dawley rats weighing an average of $90 \mathrm{~g}$ were purchased (Danhan Biolink Co.), and after adaptation of one week on rat chow (Sam Yang Co.), were randomly divided to 3 groups of 10 according to the body weight, and fed experimental diets for 6 weeks. During the experiment period, the animal room was maintained $22 \pm 2^{\circ} \mathrm{C}$ and $55 \pm 5 \%$ relative humidity with a $12 \mathrm{hr}$ light/dark cycle. Experimental diets and deionized water were offered ad libitum. A calcium free AIN-93G (Ca free) diet was prepared (Table 1). Experiment groups were divided to the control group supplied only calcium free diet $(\mathrm{F}-\mathrm{Ca})$, the group fed water-soluble calcium supplement in addition to the calcium free diet (S-Ca), and the group fed insoluble calcium supplement in addition to the calcium free diet (I-Ca).

\section{Administration of calcium supplements}

Water-soluble calcium supplement $(70 \mathrm{mg} / \mathrm{mL}$, over $90 \%$ ionizing ratio) was provided by Keimyung Foodex Co., and insoluble calcium supplement was supplied as the suspension of calcium carbonate in deionized water (70 $\mathrm{mg} / \mathrm{mL})$. Each calcium supplements was administered once a day at a constant time, $10 \mathrm{~mL} / \mathrm{kg}$ body weight, and the control group (F-Ca) was exposed to the identical stress by administering deionized water orally through a gavage needle.

Dietary consumption rate and weight measurement

Dietary consumption rate was measured once a day, and body weight was measured two times a week at the same times, and the diet efficiency was calculated by dividing the weight gain during the experimental period by the diet consumption amount.

\section{Sample collection}

After 6 weeks of feeding, rats were fasted overnight and the urine and feces were collected, anesthetized with

Table 1. Composition of experimental diets (g/kg of diet)

\begin{tabular}{lr}
\hline Ingredient & Calcium free diet \\
\hline Casein & 200 \\
Corn starch & 592.486 \\
Sucrose & 100 \\
Soybean oil & 70 \\
Cellulose & 50 \\
t-Butylhydroquinone & 0.014 \\
Min-mix ${ }^{2)}$ & 35 \\
Vit-mix & 10 \\
L-Cystine & 3 \\
Choline bitartrate & 2.50
\end{tabular}

\footnotetext{
${ }^{1)}$ AIN-93G mineral mixture (Ca free).

${ }^{2)}$ AIN-93VX vitamin mixture.
}

ether and killed. The blood collected from the aorta was centrifuged at $3000 \mathrm{rpm}$ for $20 \mathrm{~min}$, the serum was separated, and stored frozen at $-70^{\circ} \mathrm{C}$. In addition, the amount of calcium intake during the last 3 days of feeding and the amount of calcium excreted in the feces were measured, and the apparent calcium absorption rate was calculated.

\section{Biochemical analysis}

Serum calcium content was measured by an automatic absorption analyzer applying the TECHNICON $\mathrm{CHEM}^{\mathrm{TM}}$ system, and alkaline phosphatase (ALP) activity was analyzed using a kit based on the Kind and King method (12). Serum osteocalcin content was analyzed by an osteocalcin radioimmuno-assay kit (Brahams Co.). Deoxypyridinoline and creatinine content were analyzed using a collagen crosslinks kit (Metra biosystems Inc. USA) by ELISA. The crosslinks value was the value obtained by dividing deoxypyridinoline content by creatinine content. Feces were ashed and the calcium content was analyzed by atomic absorption spectrophotometer (Hitachi Inc., Japan).

\section{Bone mineral density and bone mineral content meas- urement}

At 6 weeks of feeding, the anesthetic pentobabobital sod. (Han Lim Pharmaceuticals) was injected intraperitoneally, at $1 \mathrm{~mL} / \mathrm{kg}$ dose, and using the dual energy x-ray absorptionmetry (DEXA) FIXImus (LUNAR, Madison, WI, USA), the bone mineral density (BMD) and bone mineral content (BMC) of the spine, the femur, and the tibia were measured.

\section{Statistical analysis}

Experiment results were presented as a mean and standard deviation using the SPSS program (12.0), the comparison among experiment groups was performed by one way ANOVA, and their significance was validated by Duncan's multiple range test $(\mathrm{p}<0.05)$, and the comparison of the absorption rate of calcium supplements and calcium efficiency was analyzed by independent sample t-test.

\section{RESULTS AND DISCUSSION}

Diet and calcium intake, weight gain, and food efficiency ratio

Dietary intake, calcium intake, and the amount of weight gain according to the types of calcium supplements are shown in Table 2. For the insoluble calcium supplemented group, weight gain and average dietary intakes were significantly higher. Similarly, the calcium consumption rate showed a trend towards being higher, 
Table 2. Diet and calcium intake, weight gain and food efficiency ratio of rats fed different calcium supplements

\begin{tabular}{ccccc}
\hline Group $^{1)}$ & Dietary intake (g/day) & Calcium intake (g/day) & Weight gain (g/day) & Food efficiency ratio \\
\hline F-Ca & $16.10 \pm 0.77^{\mathrm{b}}$ & - & $4.19 \pm 0.27^{2) \mathrm{b} 3)}$ & $0.26 \pm 0.01^{\mathrm{NS} 4)}$ \\
S-Ca & $15.87 \pm 0.23^{\mathrm{b}}$ & $0.165 \pm 0.013^{\mathrm{NS}}$ & $4.06 \pm 0.55^{\mathrm{b}}$ & $0.26 \pm 0.04$ \\
I-Ca & $17.60 \pm 0.74^{\mathrm{a}}$ & $0.175 \pm 0.009$ & $4.67 \pm 0.26^{\mathrm{a}}$ & $0.27 \pm 0.01$ \\
\hline
\end{tabular}

${ }^{15}$ F-Ca: rats fed only calcium free diet, S-Ca: rats fed Ca free diet and soluble calcium supplement, I-Ca: rats fed Ca free diet and insoluble calcium supplement. ${ }^{2)}$ Mean \pm SD. ${ }^{3)}$ Values with different superscripts within the column are significantly different at $\mathrm{p}<0.05 .{ }^{4)}$ Not significantly different.

but a significant difference was not detected. The results for the control group (calcium free diet) were similar to those of a study by Lee and Oh (13) that restricted calcium intake, and where the diet consumption rate and weight gain both decreased. In the water-soluble calcium supplemented group, we speculate that the calcium ionized easily due to its high solubility, causing it to taste bitter and reducing the diet consumption rate.

\section{Senum and unine composition}

The results for the serum calcium content and bone formation markers, alkaline phosphatase and osteocalcin, are shown in Table 3. Serum calcium in the insoluble calcium supplemented group was $9.95 \mathrm{mg} / \mathrm{dL}$ and significantly higher than in the control group. The water-soluble calcium supplemented group was not significantly different from the other groups. The serum alkaline phosphatase in the control group was 183.90 IU/L, which was considered high. There was no difference detected between the two calcium supplemented groups for the alkaline phosphatase levels. The level of osteocalcin among the groups was not significantly different. Changes in the serum calcium showed a similar trend to results reported by Lee and Oh (13) where serum calcium was significantly low in the low calcium consumption group. However, our results were different from those of others who reported that serum calcium concentrations were maintained at a constant level regardless of the calcium content of the diet $(14,15)$. In our study, the calcium free diet was considered the basic diet, and hence, different from a report on the homeostasis of serum calcium concentrations (16). In addition, the weight gain of the insoluble calcium supplemented group was high. Hence, it was considered that, although the difference was not significant, calcium supplements that were administered according to body weight mediated effects on serum calcium.

Serum alkaline phosphatase and osteocalcin are markers of bone formation, and their serum concentrations have been shown to increase when osteoblast activity is increased (17). Here, the alkaline phosphatase level in the control group was high, which was attributed to a calcium free diet where the skeleton could not grow normally causing an increased in vivo demand for bone formation and enhanced osteoblast activity. This is similar to results reported by Hamalainen (18) where, during calcium deficiency, alkaline phosphatase activity was increased.

Table 4 reveals that there was no significant difference in the urine deoxypyridinoline levels among the experimental groups. The crosslinks value was significantly higher in the control group than those in the calcium supplemented groups, but no difference was observed between the water-soluble and insoluble calcium

Table 3. Serum calcium, alkaline phosphatase (ALP) and osteocalcin of rats fed different calcium supplements

\begin{tabular}{cccc}
\hline Group $^{1)}$ & Serum calcium $(\mathrm{mg} / \mathrm{dL})$ & ALP $(\mathrm{IU} / \mathrm{L})$ & Osteocalcin $(\mathrm{ng} / \mathrm{mL})$ \\
\hline F-Ca & $9.23 \pm 0.33^{2) \mathrm{b} 3)}$ & $183.90 \pm 41.19^{\mathrm{a}}$ & $1.80 \pm 0.46^{\mathrm{NS} 4)}$ \\
S-Ca & $9.70 \pm 0.60^{\mathrm{ab}}$ & $120.00 \pm 30.97^{\mathrm{b}}$ & $1.66 \pm 0.21$ \\
I-Ca & $9.95 \pm 0.48^{\mathrm{a}}$ & $106.10 \pm 19.57^{\mathrm{b}}$ & $1.40 \pm 0.25$ \\
\hline
\end{tabular}

${ }^{1)}$ Refer to Table $1 .{ }^{2)}$ Mean \pm SD. ${ }^{3)}$ Values with different superscripts within the column are significantly different at $\mathrm{p}<0.05$ by Duncan's multiple range test. ${ }^{4)}$ Not significantly different.

Table 4. Urine deoxypyridinoline, creatinine and crosslinks value of rats fed different calcium supplements

\begin{tabular}{cccc}
\hline Group $^{1)}$ & Deoxypyridinoline $(\mathrm{nM})$ & Creatinine $(\mathrm{mM})^{\mathrm{NS}}$ & Crosslinks value $^{4)}(\mathrm{nM} / \mathrm{mM})$ \\
\hline F-Ca & $1608.00 \pm 293.43^{2) \mathrm{NS}}$ & $\left.6.32 \pm 2.76^{\mathrm{NS}}\right)$ & $258.30 \pm 32.08^{\mathrm{a} 5}$ \\
S-Ca & $1266.80 \pm 238.91$ & $8.17 \pm 1.29$ & $154.54 \pm 47.07^{\mathrm{b}}$ \\
I-Ca & $1301.25 \pm 135.91$ & $7.70 \pm 2.22$ & $168.95 \pm 16.23^{\mathrm{b}}$ \\
\hline
\end{tabular}

${ }^{1)}$ Refer to Table $1 .{ }^{2)}$ Mean \pm SD. ${ }^{3)}$ Not significantly different. ${ }^{4)}$ Crosslinks value $=$ Deoxypyridinoline/Creatinine. ${ }^{5)}$ Values with different superscripts within the column are significantly different at $\mathrm{p}<0.05$ by Duncan's multiple range test. 
Table 5. Calcium intake, fecal calcium excretion, and calcium absorption in rats fed different calcium supplements

\begin{tabular}{cccc}
\hline Group $^{1)}$ & Calcium intake (mg/day) & Fecal calcium excretion (mg/day) & Apparent calcium absorption (\%) \\
\hline S-Ca & $229.46 \pm 17.29^{2) N S}$ & $15.65 \pm 3.20^{\text {NS3 }}$ & $93.17 \pm 1.89^{\text {NS }}$ \\
I-Ca & $239.66 \pm 10.25$ & $20.80 \pm 5.93$ & $91.30 \pm 1.76$
\end{tabular}

${ }^{1)}$ Refer to Table $1 .{ }^{2)}$ Mean \pm SD. ${ }^{3)}$ Not significantly different.

supplemented groups. Deoxypyridinoline is a crosslinked collagen present in the skeleton, and excreted in the urine with collagen byproducts as a result of osteoclast action $(19,20)$. We speculate that in the control group, where calcium intake was restricted, the bone resorption rate was increased and the crosslinks value comparable to rats whose bone resorption rate was increased to $202.6 \sim 280.4 \mathrm{nM} / \mathrm{mM}$ due to oophorectomy (19). Considering the results for the blood bone formation markers and urine bone resorption markers, no significant difference was detected between the supplemented groups based on the calcium solubility.

\section{The apparent calcium absoption rate}

The calcium absorption rates were calculated from the dietary calcium intake rates and calcium excretion rates in feces for 3 days, prior to completion of the experiment (Table 5). A trend toward high calcium intake and excretion was observed in the insoluble calcium group, and a higher absorption rate observed for the water-soluble group, but a significant difference was not detected. These results were similar to those reported by Benson et al. (21) where an increased calcium intake resulted in a decreased endogenous calcium reabsoprtion rate.

Bone mineral density (BMD) and bone mineral content (BMC)

The BMD of the spine at 6 weeks after consuming the experimental diets was significantly higher in the calcium supplement groups, but a difference based on the solubility of the calcium supplements was not detected (Table 6). The spinal BMDs were as follows: 0.043 $\mathrm{g} / \mathrm{cm}^{2}$ in the control group, $0.125 \mathrm{~g} / \mathrm{cm}^{2}$ in the watersoluble calcium supplemented group, and $0.129 \mathrm{~g} / \mathrm{cm}^{2}$ in the insoluble calcium supplemented group. Similarly, the BMC in the spine of the control group was significantly low. In the case of the femur and the tibia, both the BMD and BMC were significantly higher in the insoluble calcium supplemented group, making it appear that insoluble calcium supplements could be beneficial to bone health. Since the weight gain of the insoluble calcium supplemented group was high, it was speculated that calcium supplements that were administered according to weight mediated effects on BMD and BMC. In addition weight is considered to be an important factor for BMD and BMC (22). Thus to examine actual bone health, each value was converted to a value reflecting the body weight. Per $100 \mathrm{~g}$ of body weight the BMD was highest in all areas, including the femur, for the water-soluble calcium supplemented group, though the BMC per $100 \mathrm{~g}$ of body weight was not different between calcium supplemented groups. In other words, water-soluble calcium supplements were considered to be more effective than the insoluble calcium supplements. However, the calcium efficiency for each bone area between the two calcium supplements was not significantly different (Table 7). We speculate this may be due to the relatively short period of calcium supplementation of only 6 weeks. Thus the efficiency of the two calcium supplements was comparable within the restrictions of the experimental conditions.

In conclusion, the effects of the two calcium supplements with different solubility on the markers of blood

Table 6. Bone mineral density (BMD) and bone mineral content (BMC) of rats fed different calcium supplements

\begin{tabular}{cllccc}
\hline Bone & Group $^{1)}$ & BMD $\left(\mathrm{g} / \mathrm{cm}^{2}\right)$ & BMD $\left(\mathrm{g} / \mathrm{cm}^{2}\right) / 100 \mathrm{~g}$ wt & BMC $(\mathrm{g})$ & BMC $(\mathrm{g}) / 100 \mathrm{~g}$ wt \\
\hline \multirow{3}{*}{ Spine } & F-Ca & $\left.0.043 \pm 0.006^{\mathrm{b} 3}\right)$ & $0.012 \pm 0.001^{\mathrm{c}}$ & $0.133 \pm 0.026^{2) \mathrm{b}}$ & $0.025 \pm 0.003^{\mathrm{b}}$ \\
& S-Ca & $0.125 \pm 0.019^{\mathrm{a}}$ & $0.042 \pm 0.005^{\mathrm{a}}$ & $0.504 \pm 0.086^{\mathrm{a}}$ & $0.114 \pm 0.013^{\mathrm{a}}$ \\
& I-Ca & $0.129 \pm 0.015^{\mathrm{a}}$ & $0.036 \pm 0.004^{\mathrm{b}}$ & $0.545 \pm 0.098^{\mathrm{a}}$ & $0.110 \pm 0.011^{\mathrm{a}}$ \\
\hline \multirow{3}{*}{ Femur } & F-Ca & $0.096 \pm 0.007^{\mathrm{c}}$ & $0.027 \pm 0.002^{\mathrm{c}}$ & $0.175 \pm 0.014^{\mathrm{c}}$ & $0.051 \pm 0.002^{\mathrm{b}}$ \\
& S-Ca & $0.170 \pm 0.016^{\mathrm{b}}$ & $0.058 \pm 0.001^{\mathrm{a}}$ & $0.326 \pm 0.040^{\mathrm{b}}$ & $0.112 \pm 0.005^{\mathrm{a}}$ \\
& I-Ca & $0.192 \pm 0.013^{\mathrm{a}}$ & $0.054 \pm 0.003^{\mathrm{b}}$ & $0.377 \pm 0.037^{\mathrm{a}}$ & $0.108 \pm 0.007^{\mathrm{a}}$ \\
\hline \multirow{3}{*}{ Tibia } & F-Ca & $0.066 \pm 0.002^{\mathrm{c}}$ & $0.019 \pm 0.001^{\mathrm{c}}$ & $0.157 \pm 0.006^{\mathrm{c}}$ & $0.045 \pm 0.002^{\mathrm{b}}$ \\
& S-Ca & $0.108 \pm 0.008^{\mathrm{b}}$ & $0.037 \pm 0.001^{\mathrm{a}}$ & $0.264 \pm 0.030^{\mathrm{b}}$ & $0.091 \pm 0.009^{\mathrm{a}}$ \\
& I-Ca & $0.115 \pm 0.007^{\mathrm{a}}$ & $0.032 \pm 0.002^{\mathrm{b}}$ & $0.291 \pm 0.029^{\mathrm{a}}$ & $0.083 \pm 0.007^{\mathrm{a}}$ \\
\hline
\end{tabular}

${ }^{1)}$ Refer to Table $1 .{ }^{2)}$ Mean \pm SD. ${ }^{3)}$ Values with different superscripts within the column are significantly different at $\mathrm{p}<0.05$ by Duncan's multiple range test. 
Table 7. Calcium efficiency of rats fed different calcium supplements

\begin{tabular}{cccc}
\hline Group $^{1)}$ & \multicolumn{3}{c}{ Calcium efficient $^{2)}$} \\
\cline { 2 - 4 } & Spine & Femur & Tibia \\
S-Ca & $0.757 \pm 0.090^{3) \mathrm{NS}}$ & $1.027 \pm 0.081^{\text {NS4) }}$ & $0.652 \pm 0.032^{\text {NS }}$ \\
I-Ca & $0.741 \pm 0.062$ & $1.083 \pm 0.060$ & $0.647 \pm 0.042$ \\
\hline
\end{tabular}

${ }^{1)}$ Refer to Table $1 .{ }^{2}$ Calcium efficiency = BMD $\left(\mathrm{g} / \mathrm{cm}^{2}\right) /$ average calcium intake (g/day). ${ }^{3)}$ Mean \pm SD. ${ }^{4)}$ Not significantly different.

and urine calcium metabolism and calcium efficiency for each bone area were not different. Nonetheless, the water-soluble calcium supplements were found to be beneficial to BMD in terms of weight bearing. Thus, additional studies on the bioavailability of water-soluble calcium supplements should be conducted in the future.

\section{REFERENCES}

1. Allen LH. 1982. Calcium bioavailability and adsorption. Am J Clin Nutr 35: 738-808.

2. Choi MJ. 2001. Effects of exercise and calcium intake on blood pressure and blood lipids in premenopausal women. Kor J Nutr 34: 62-68.

3. McKane WR, Khosla S, Egan KS, Robins SP. 1996. Role of calcium intake in modulating age-related increases in parathyroid function and bone resorption. Am J Clin Endocrinol Metab 81: 1699-1703.

4. Sinha R, Smith JC, Soares JH. 1988. The effect of dietary calcium on bone metabolism in young and aged female rats using a short-term in vivo model. Am J Nutr 118: 1217-1222.

5. Gordon, GS, Vaughn C. 1987. Calcium and osteoporosis. Am J Nutr 116: 319-322.

6. Greger JL, Krzykowski CE, Khanzen RR, Krashoc CL. 1987. Mineral utilization by rats fed various commercially available calcium supplements or milk. Am J Nutr 117: 717-724.

7. Heller HJ, Greer LG, Haynes SD, Pondexter JR, Pak CY. 2000. Pharmacokinetic and pharmacodynamic comparison of two calcium supplements in postmenopausal women. J Clin Pharmacol 40: 1237-1244.

8. Hanzlik RP, Fowler SC, Fisher DH. 2005. Relative bioavailability of calcium from calcium formate, calcium citrate, and calcium carbonate. J Pharmacol Exp Ther 313: 1217-1222.

9. Sakhaee K, Bhuket T, Adams-Huet B, Sudhaker Rao D. 1999. Meta-analysis of calcium bioavailability: a comparison of calcium citrate with calcium carbonate. Am $J$ Ther 6: 313-321.
10. Martini L, Wood RJ. 2002. Relative bioavailability of calcium-rich dietary sources in the elderly. Am J Clin Nutr 76: $1345-1350$.

11. Heaney RP, Dowell MS, Bierman J, Hale CA, Bendich A. 2001. Absorbability and cost effectiveness in calcium supplementation. J Am Coll Nutr 20: 239-246.

12. Kind PRN, King ER. 1954. Estimation of plasma phosphatase by determination of hydrolyzed phenol with aminoantipyrine. J Clin Pathol 3: 332-334.

13. Lee YS, Oh JH. 1995. Effects of bovine bone ash and calcium phosphate on calcium metabolism in postmenopausal osteopotosis model rats. Kor J Nutr 28: 434-441.

14. Hietala EL. 1993. The effect of ovariectomy on periosteral bone formation and bone resorption in adult rats. Bone Miner 20: 57-65.

15. Sung CJ. 1995. Effects of calcium intake on calcium, sodium and potassium metabolism in young and adult female rats. Kor J Nutr 28: 309-320.

16. Chang YE, Chung HK, Chang NS, Lee HS. 1997. The effects of dietary protein and calcium levels on calcium and bone metabolism in growing rats. Kor J Nutr 30: 266-276.

17. Kleerekoper M. 1996. Biochemical markers of bone remodeling. Am J Med Sci 312: 270-277.

18. Hamalainen MM. 1994. Bone repair in calcium-deficient rats: Comparison of xylitol+calcium carbonate with calcium carbonate, calcium lactate and calcium citrate on the repletion of calcium. Am J Nutr 124: 874-881.

19. Choi MJ, Yu TS. 2004. Effects of red-yeast-rice supplementation on bone mineral density and bone mineral content in overiectomized rats. Kor J Nutr 37: 423-430.

20. Eyre DR. 1996. Biochemical markers of bone turnover. In Primer on the metabolic bone diseases and disorder of mineral metabolism. Favus MJ, ed. Raven Press Inc, New York. p114-118.

21. Benson JD, Emery RS, Thomas JW. 1969. Effects of previous calcium intake on adaptation to low and high calcium diets in rats. Am J Nutr 97: 53-60.

22. Choi MJ, Ho HJ. 2003. Effects of soy protein and isoflavones on bone mineral density in growing female rat. Kor J Nutr 36: 359-367.

(Received September 14, 2007; Accepted December 13, 2007) 